\title{
ADHERENCE TO OPIOID THERAPY IN PATIENTS WITH CHRONIC NON-CANCER PAIN ATTENDING A PAIN CLINIC IN MALAYSIA
}

\author{
HUSSAM MIZHER ${ }^{1}$, CHE S ZIN ${ }^{1 *}$, ASWEEN R SANI ${ }^{1}$, ABDUL HADI BIN MOHAMED $^{2}$, TAN H LING ${ }^{3}$, MUNIRA M IZAT ${ }^{3}$ \\ ${ }^{1}$ Department of Pharmacy Practice, Kulliyyah of Pharmacy, International Islamic University Malaysia, Bandar Indera Mahkota Campus, \\ Jalan Sultan Ahmad Shah, 25200 Kuantan, Pahang Darul Makmur, Malaysia. ${ }^{2}$ Department of Anesthesiology and Intensive Care, Kulliyyah \\ of Medicine, International Islamic University, Selangor, Malaysia. ${ }^{3}$ Pain Clinic, Hospital Kuala Lumpur, Jalan Pahang, 50586 Federal \\ Territory of Kuala Lumpur, Malaysia. Email: chesuraya@iium.edu.my
}

Received: 25 August 2018, Revised and Accepted: 19 September 2018

\section{ABSTRACT}

objectives: This study examined the adherence to opioid therapy in patients with chronic noncancer pain (CNCP). The prevalence of opioid use and pain scores was also explored.

Methods: This cross-sectional study was conducted among patients with noncancer pain attending a pain clinic at a tertiary hospital in Malaysia from August 2016 to February 2017. All patients prescribed with any of the five available opioids (morphine, oxycodone, fentanyl, buprenorphine, and dihydrocodeine) were included in the study, and their medical and prescription records were assessed for further information on opioid use such as the type of opioid, dose, frequency, and duration. The prevalence of opioid use was calculated by dividing the number of opioid users and the total number of patients attending the pain clinic during the study. Adherence was calculated for patients with long-term opioid therapy (>90 days/ year) and measured using the medication possession ratio (MPR). This was derived by sum up the total days covered with medication in the last 365 days; and then divide that by the total days, the medication was prescribed over the same period. A cutoff point of $80 \%$ or more was considered as adherence. The pain intensity score was assessed through a numerical scale from 0 (no pain) to 10 (worst possible pain) at four different points (now, on average, least in the last $24 \mathrm{~h}$, and worst in the last $24 \mathrm{~h}$ ).

Results: A total of 555 patients with various noncancer pain conditions attended the pain clinic during the study. The prevalence of opioid use among these patients was $13.5 \%(n=74 / 555)$. Of these, $24.3 \%(n=18 / 74)$ of patients using opioids for long term $(>90$ days $)$ and were included in the adherence measure. $78 \%(n=14 / 18)$ of these long-term opioid users were adherent to opioid therapy with a reported MPR $>80 \%$. $22 \%(n=4 / 18)$ of patients showed nonadherence to opioid therapy with a reported MPR $<80 \%$. The mean pain score for both adherent and nonadherent groups was $5 / 10$, and there was no statistical difference between the two groups.

Conclusion: The preliminary results of this study demonstrated that the majority of patients with chronic opioid use adhered to their prescribed opioids. The prevalence of opioid use among patients with noncancer pain was low, and the number of patients using opioid for the long term was $\sim 20 \%$ which is similar to the finding from the previous study. The future research is required to evaluate the clinical outcomes in patients with CNCP using opioid for long term particularly in nonadherent patients.

Keywords: Opioid, Non-cancer pain, Adherence, Medication possession ratio, Chronic pain, prevalence.

(C) 2018 The Authors. Published by Innovare Academic Sciences Pvt Ltd. This is an open access article under the CC BY license (http://creativecommons. org/licenses/by/4. 0/) DOI: http://dx.doi.org/10.22159/ajpcr.2018.v11s3.29960

\section{INTRODUCTION}

The pain is defined by The International Association for the Study of Pain as "an unpleasant sensory and emotional experience associated with actual or potential tissue damage or described regarding such damage [1]." Pain is one of the most prevalent health problems [2] and is considered the fifth vital sign [3]. Most of the health conditions (such as cancer, rheumatoid arthritis, fibromyalgia and postherpetic neuralgia, and chronic back pain) are associated with pain in which pain control remains the top priority for these health conditions. Chronic pain can be defined as the pain that persists for 3 months, or more and $\backslash$ or exceeds the healing time required for the damaged tissue [2]. This type of pain is considered among the leading reasons for increasing the healthcare services demand and cost, and perhaps most importantly, reducing the patients' quality of life [4]. Pain relief remains the cornerstone of the treatment for pain especially when there is no cure for the underlying diseases [4]. Opioids are strong analgesics that have been used for centuries for the treatment of pain. In the last few decades, the use of opioid has dramatically increased in managing chronic noncancer pain (CNCP), despite the fact that the use in this CNCP condition is controversial as the available evidence is limited to short-term efficacy and side effects [5]. A number of concerns are raised regarding the long-term use of opioids in CNCP which include increased risks of opioid tolerance, abuse, addiction, and opioid overdose death. It is reported that in the United States, the opioid overdose death has increased four-fold in the last 10 years [6]. Adherence to opioid treatment is important in achieving the treatment goals of relieving pain, improving quality of life, and preventing the unwanted consequences such as addiction and abuse or misuse. Adherence is defined as "the extent to which a patient acts in accordance with the prescribed interval and dose of a dosing regimen[7]," or it also can be defined as the "active, voluntary, and collaborative involvement of the patient in a mutually acceptable course of behavior to produce a therapeutic result [8]." Poor adherence is accompanied by the increase in morbidity and mortality, treatment cost, and worsening in the overall health outcomes $[9,10]$. To date, there is limited data available on the adherence to opioid therapy in CNCP patients in Malaysia. As such, this study was prompted to investigate the adherence to opioids in patients with CNCP. The prevalence of opioid use and pain intensity score was also evaluated and correlated with the adherence measure 


\section{METHODS}

\section{Study type}

This was a retrospective cross-sectional clinical study conducted at a pain clinic of a tertiary hospital setting in Malaysia. The approval from the Medical Research Ethical Committee, Ministry of Health Malaysia was obtained before conducting the study. Only patients, who gave consent form, were included in the study.

\section{Study design and data sources}

Patient's recruitment was carried out between August 2016 and February 2017 during their scheduled visit to pain the clinic. The patients were recruited into the study if they met the following inclusion criteria: A current opioid user taking one or more of the opioids included in the study (morphine, dihydrocodeine, oxycodone, oxycodone/naloxone, fentanyl, and buprenorphine), diagnosed with a noncancer pain, and age of 18 years or older. The patients were excluded if they have a history of opioid substance abuse or received injectable opioids as they are considered in-patients. Cancer pain patients were also excluded from the study. The included patients were further categorized into short-term and long-term opioid users based on the days of opioid use. The long-term opioid use was defined as using prescribed opioid for more than 90 days in the last 365 days, and this group of patients was included in the adherence measures and final analysis.

Prescriptions and medical records of long-term opioid users included in the study were reviewed. Data included the name and opioid type, date dispensed, quantity dispensed, and total days of drug supply were extracted from the prescription records. Patients' characteristics, including age, gender, and diagnosis, were also recorded.

\section{Outcome measures}

\section{Prevalence}

The prevalence of opioid use among noncancer pain patients was calculated by counting the total number of patients using opioid therapy and then dividing that by the total number of pain patients attending the clinic during the study.

\section{Adherence measure}

Adherence was calculated among the long-term opioid users using the medication possession ratio (MPR). MPR is generally expressed as the proportion of days in which the medication is supplied over a specified period [11]. In the present study, once a long-term patient was identified, all their previous pharmacy and medical records on opioid use were revised. Data during the observation period (the last 365 or subsequent for patients with $<365$ days use) days were included in the calculation. The total days of drug supply were measured by counting the days for all prescriptions within the observation period. The following formula was used to calculate the MPR in this study [12]:

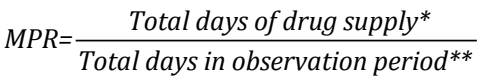

*The total days of drug supply was measured by calculating the period (in days) for all prescriptions within the observation period. ${ }^{* *}$ The total days in the observation period is considered as the previous year (365 days or subsequent) from the end date.

The end date was the date when patients were seen at the pain clinic and assessed for their pain level. The observation period is the sum-up of the days in which the patient is covered with an opioid prescription between the index date until the end date. The index date is the first day of opioid prescription in the last 365 days. In other words, the previous 365 days are the observation period for the patients who were taking opioid for 365 days or more, and the total days of opioid usage is considered for patients with $<365$ days usage. For example, both patients A and B met the inclusion criteria, while patient A was under opioid for 2 years, and patient B for 200 days, then the observation period for both patients will be 365 and 200 days, respectively.

A percentage value of $80 \%$ or more for MPR is considered as adherent, and a value of $<80 \%$ as nonadherent [11]. When the prescription was dispensed before the stipulated date, the overlapping days between prescription refills were excluded from the observation period to avoid adherence $>100 \%$ [13]

\section{Pain intensity score}

The pain score was evaluated using a numerical pain scale from 0 to 10 . Each patient was asked about their pain level at four different aspects (now, worst in last $24 \mathrm{~h}$, least in the last $24 \mathrm{~h}$, and pain on average) based on a verbal scale from 0 to 10 , where 0 represents no pain, and 10 represents the worst imaginable pain [14]. Data were expressed as mean \pm (standard deviation [SD]) and analyzed using the Student's $t$-test for the comparison between adherent and nonadherent. Differences were considered statistically significant, if $\mathrm{p}<0.05$.

\section{RESULTS}

\section{Study subjects}

A total of 555 patients attended the pain clinic during the study, and they were diagnosed with various pain conditions such as neuropathic pain as fibromyalgia and diabetic neuropathy, or inflammatory as osteoarthritis or other musculoskeletal diseases (Fig. 1).

Of 555 patients, 74 patients were using the opioid therapy and the prevalence of opioid use among pain patients for was $13.5 \%$. Of the 74 patients using opioids, a total of 18 patients were long-term opioid users and included in the analysis. Details of patients' characteristics are summarized in Table 1 . There were $61 \%(n=11 / 18)$ of males and $39 \%(n=7 / 18)$ of females included in this study. The mean age was 53.2 years old \pm SD (11.3). The main diagnosis was back pain $33 \%(n=6 / 18)$, followed by bilateral hip pain $11 \%(n=2 / 18)$.

Table 1: Demographic details of long-term opioid patients $(n=18)$

\begin{tabular}{|c|c|}
\hline Characteristics & $\begin{array}{l}\text { Number of } \\
\text { patients }(\%)\end{array}$ \\
\hline \multicolumn{2}{|l|}{ Age } \\
\hline Mean \pm SD & $53.2 \pm 11.3$ \\
\hline \multicolumn{2}{|l|}{ Age-group } \\
\hline $18-29$ & - \\
\hline $30-39$ & $3(17)$ \\
\hline $40-49$ & $5(28)$ \\
\hline $50-59$ & $4(22)$ \\
\hline$\geq 60$ & $6(33)$ \\
\hline \multicolumn{2}{|l|}{ Gender } \\
\hline Male & $11(61)$ \\
\hline Female & $7(39)$ \\
\hline \multicolumn{2}{|l|}{ Diagnosis } \\
\hline Back pain & $6(33)$ \\
\hline Bilateral hip pain & $2(11)$ \\
\hline Fibromyalgia & $1(5.5)$ \\
\hline Postsurgical pain syndrome & $1(5.5)$ \\
\hline Chronic knee pain & $1(5.5)$ \\
\hline Sensory neuropathy & $1(5.5)$ \\
\hline Neuropathic & $1(5.5)$ \\
\hline Brachial plexus injury with neuropathic pain & $1(5.5)$ \\
\hline Postherpetic neuralgia & $1(5.5)$ \\
\hline Diabetic neuropathy & $1(5.5)$ \\
\hline Chronic venous insufficiency. & $1(5.5)$ \\
\hline Bilateral osteoarthritis & $1(5.5)$ \\
\hline \multicolumn{2}{|l|}{ Type of opioid } \\
\hline Dihydrocodeine & $11(61)$ \\
\hline Oxycodone & $4(22)$ \\
\hline Morphine & $1(5.5)$ \\
\hline Fentanyl & $1(5.5)$ \\
\hline Buprenorphine & $1(5.5)$ \\
\hline
\end{tabular}




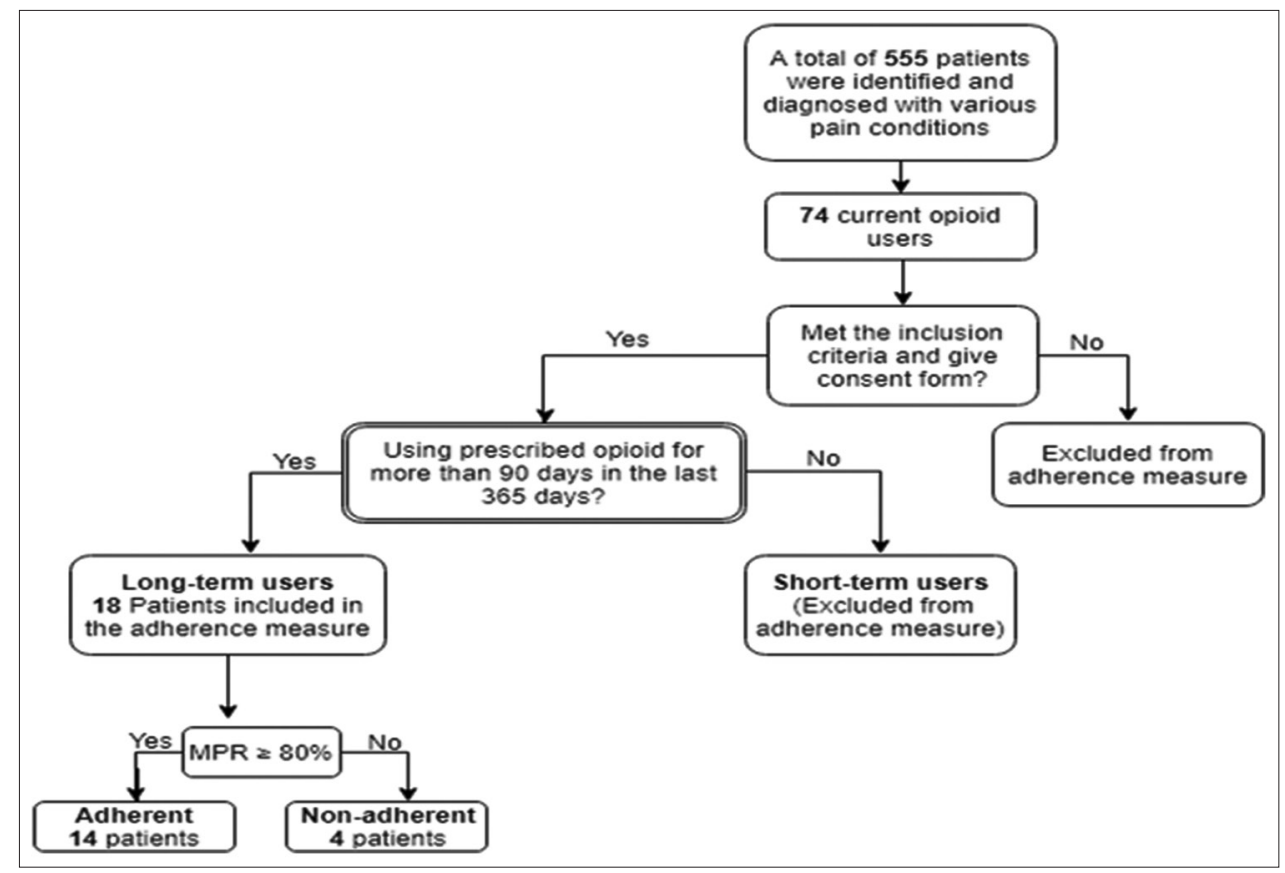

Fig. 1: Study subject flowchart

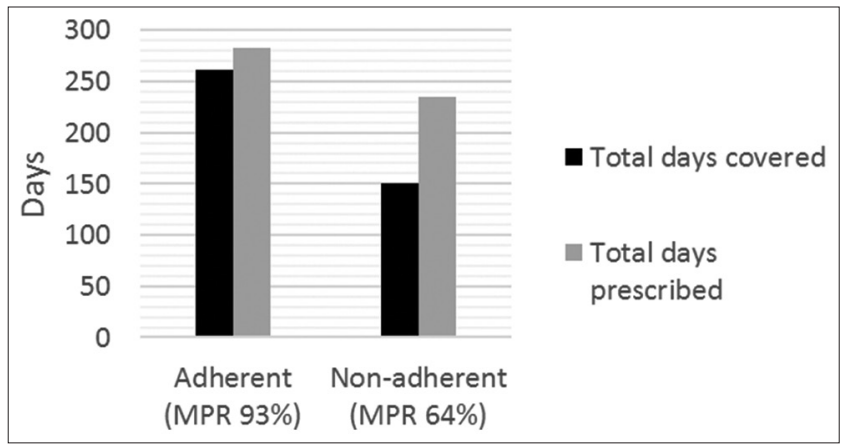

Fig. 2: Days cover with opioids in adherent and nonadherent groups

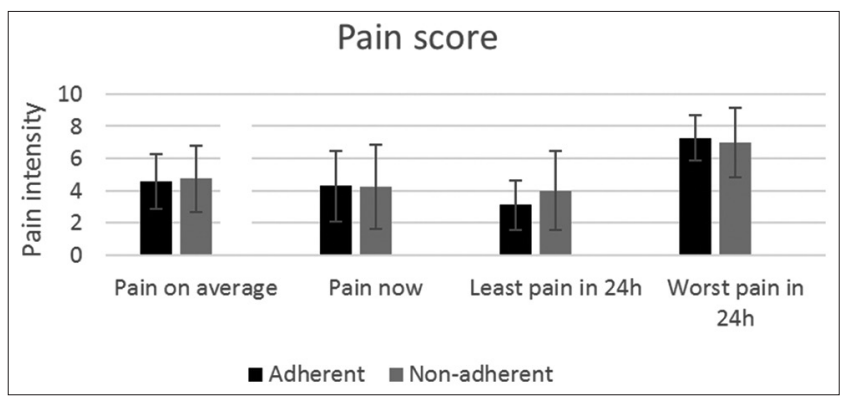

Fig. 3: Comparison of pain scores between adherent and nonadherent groups

The most prescribed opioid was dihydrocodeine 61\% ( $\mathrm{n}=11 / 18)$, followed by oxycodone $22 \%(\mathrm{n}=4 / 18)$, and then morphine, fentanyl, and buprenorphine $5.5 \%(n=1 / 18)$ for each of them.

\section{Adherence measurement using MPR}

Of the 18 patients, 14 patients $(77.8 \%)$ adhered to their prescribed regimen as their MPR value was $80 \%$ or more. Four patients $(22.2 \%)$ showed nonadherence with MPR value of $<80 \%$. The mean total days covered for adherent patients was 261 days compared with 151 for the nonadherent group, while the mean total days prescribed for the adherent and nonadherent groups

were 282 and 234 days, respectively. The mean MPR for the adherent was $93 \%$ and for the nonadherent was $64 \%$ (Fig. 2).

\section{Pain intensity score}

As per Fig. 3, both adherent and nonadherent groups reported the mean pain score as five points on the scale as the average pain. Similarly, both groups ranked seven points for the worst pain over the last $24 \mathrm{~h}$. Pain now and the least pain in the adherent group were 4 and 3 which are slightly lesser compared with nonadherent whose pain was 5 and 4 , respectively. There was no statistical difference between the adherent and the nonadherent group at the four points.

\section{DISCUSSION}

The finding from this study demonstrated that the majority of patients with long-term opioid therapy for CNCP were adherent to their opioid therapy. The nonadherence to opioid therapy was shown in $22 \%$ of patients. This finding is consistent with previous studies that reported rates of nonadherence in chronic pain patients from $8 \%$ to $62 \%[15,16]$. Among opioid users, nonadherence was reported from as low as $2 \%$ to $53 \%$, the wide range was reported mainly due to the definition of adherence, as some studies considered nonadherence based on medication underuse only, while some other authors measured medication under or overuse as nonadherence [17-19]. Factors, such as increasing frequency of dosing and pain intensity, were reported positively correlated with poor adherence. Other factors, such as concern about addiction and side effects, were also related to affect patient adherence to opioid therapy [19]. To ensure patients adherent to the opioid therapy and to achieve the treatment goals, all the related factors affecting the adherence need to be improved. The present study was also demonstrated that the prevalence of opioid use among patients with noncancer pain was $13.5 \%$. The prevalence from this study is low as compared with a recent study of long-term therapy in CNCP conducted in a pain clinic in Germany with a prevalence of 51\% [20]. The big difference could be justified because the opioid use is more common in their population. A low prevalence in the present study may also be explained by the total opioid consumption in Malaysia is much lower (0.3643 DDD/1000 population/day) compared to other 
countries such as Australia and Nordic countries ( 9 and 18 DDD/1000 population/day, respectively) [21].

The low prevalence of opioid use in this current study may also be associated with the low prevalence of chronic pain patients in Malaysia (7\%) [22] as compared to other countries such as in the developed countries (10-50\%) [4] Europe (20\%) [23] and UK (35.0\% to 51.3\% [24]. Patients, undergoing opioid therapy, are assumed to report lower pain scores. Thus, uncontrolled pain is an indication of poor adherence, and physicians may need to draw attention to the patients' compliance with their therapeutic plan. In the present study, pain scores were not different among the adherent and nonadherent groups, and this could be due to disease progression or other related problems to opioid such as opioid tolerance and opioid induced-hyperalgesia. Thus, knowing that a patient is an adherent to their opioid regime while still reporting a high pain score will help the physician to investigate these other possibilities. The limitation of the study includes the fact that MPR is a measure of adherence whereas MPR estimates only the days' covered with medication in hand, while in fact; there is no guarantee whether the patient followed or not the time and dosing regimen by the physician [25]. The findings from this study give us a sight about the adherence and the prevalence of opioid use among noncancer pain patients. However, these results should be used with caution due to the limited sample size used which represents the studied site, and may not reflect the actual community.

\section{CONCLUSION}

Based on our findings, the majority of the patients were adherent with their opioid therapy; however, their pain score was not different from the nonadherent patients. This could be one of the factors related to medication overuse and subsequently could lead to other complications such as abuse and opioid overdose death. However, pain score is reported based on the patient report only which considered a subjective measure. As such, the calculation of adherence using the MPR and link that with some other objective measures will be more useful to help us to understand the underlying causes contributing to the pain scores. The future research is required to investigate factors that likely affect the adherence to correlate adherence with the opioid dose and to examine the clinical outcomes. Such a study should be conducted in a larger sample size.

\section{ACKNOWLEDGMENT}

This research was supported by research grants from the International Islamic University Malaysia (Endowment B-EDWB 14-095-0980) and the Ministry of Education Malaysia Fundamental Research Grant Scheme-FRGS 14-195-0436).

\section{AUTHOR'S CONTRIBUTIONS}

HM collected the data, analyzed the results, and drafted the manuscript. CSZ is the principal investigator who designed the study, aided in interpreting the results, and supervised the writing of the manuscript. All authors contributed to the design, implementation of the research, data collection, interpretation of the results, and approved the final manuscript.

\section{CONFLICT OF INTEREST STATEMENT}

The authors declare no conflict of interest.

\section{REFERENCES}

1. Loeser JD, Treede RD. The kyoto protocol of IASP basic pain terminology. Pain 2008;137:473-7.
2. Baron R. Mechanisms of disease: Neuropathic pain-a clinical perspective. Nat Clin Pract Neurol 2006;2:95-106.

3. Campbell JN. The fifth vital sign revisited. Pain 2016;157:3-4

4. Andrew R, Derry S, Taylor RS, Straube S, Phillips CJ. The costs and consequences of adequately managed chronic non-cancer pain and chronic neuropathic pain. Pain Pract 2014;14:79-94.

5. Manchikanti L, Atluri S, Hansen H, Benyamin RM, Falco FJ, HelmIi S, et al. Opioids in chronic noncancer pain: Have we reached a boiling point yet? Pain Physician 2014;17:E1-10.

6. Jones CM, Mack KA, Paulozzi LJ. Pharmaceutical overdose deaths, united states, 2010. JAMA 2013;309:657-9.

7. Cramer J, Rosenheck R, Kirk G, Krol W, Krystal J, VA Naltrexone Study Group 425. et al. Medication compliance feedback and monitoring in a clinical trial: Predictors and outcomes. Value Health 2003;6:566-73.

8. Delamater AM. Improving patient adherence. Clin Diabetes 2006;24:71-7.

9. Osterberg L, Blaschke T. Adherence to medication. N Engl J Med 2005;353:487-97.

10. Sokol MC, McGuigan KA, Verbrugge RR, Epstein RS. Impact of medication adherence on hospitalization risk and healthcare cost. Med Care 2005;43:521-30.

11. Andrade SE, Kahler KH, Frech F, Chan KA. Methods for evaluation of medication adherence and persistence using automated databases. Pharmacoepidemiol Drug Saf 2006;15:565-74.

12. Peterson AM, Nau DP, Cramer JA, Benner J, Gwadry-Sridhar F, Nichol M, et al. A checklist for medication compliance and persistence studies using retrospective databases. Value Health 2007;10:3-12.

13. Zin CS, Rahman NA, Ismail CR, Choy LW. Dose and duration of opioid use in patients with cancer and noncancer pain at an outpatient hospital setting in malaysia. Pain Pract 2017;17:774-81.

14. Moorthy S, Codi RS, Surendher R, Manimekalai K. Comparison of the efficacy and safety of tramadol versus tapentadol in acute osteoarthritic knee pain: A randomized, controlled trial. Asian J Pharm Clin Res 2016;9:3.

15. Broekmans S, Dobbels F, Milisen K, Morlion B, Vanderschueren S. Determinants of medication underuse and medication overuse in patients with chronic non-malignant pain: A multicenter study. Int J Nurs Stud 2010;47:1408-17.

16. Markotic F, Cerni Obrdalj E, Zalihic A, Pehar R, Hadziosmanovic Z, Pivic $\mathrm{G}$, et al. Adherence to pharmacological treatment of chronic nonmalignant pain in individuals aged 65 and older. Pain Med 2013;14:247-56

17. Matteliano D, Chang YP. Describing prescription opioid adherence among individuals with chronic pain using urine drug testing. Pain Manag Nurs 2015;16:51-9.

18. Chang YP, Chang RN. Use of prescription opioid medication among community-dwelling older adults with noncancer chronic pain. J Add Nurs 2011;22:19-24.

19. Timmerman L, Stronks DL, Groeneweg JG, Huygen FJ. Prevalence and determinants of medication non-adherence in chronic pain patients: A systematic review. Acta Anaesthesiol Scand 2016;60:416-31.

20. Elsesser K, Cegla T. Long-term treatment in chronic noncancer pain: Results of an observational study comparing opioid and nonopioid therapy. Scand J Pain 2017; 17:87-98.

21. Mary SC, C.Y, Marzida M. Use of Opioid Analgesics. Malaysia: Pharmaceutical Services Division and Clinical Research Center, Ministry of Health Malaysia. Malaysian Statistics on Medicines; 2008. p. 121-2.

22. Malaysian Association for the Study of Pain. A guide to the use of strong opioids in chronic non-cancer pain 2015;1:24.

23. Thomson L, Rait K, Miller L. Opioids in the management of persistent non-cancer pain. Anaesth Intens Care Med 2016;17:552-4.

24. Fayaz A, Croft P, Langford RM, Donaldson LJ, Jones GT. Prevalence of chronic pain in the UK: A systematic review and meta-analysis of population studies. BMJ Open 2016;6:e010364.

25. Karve S, Cleves MA, Helm M, Hudson TJ, West DS, Martin BC, et al. Prospective validation of eight different adherence measures for use with administrative claims data among patients with schizophrenia. Value Health 2009;12:989-95. 